\title{
HETEROGENEIDADE ESTRUTURAL NAS RELAÇÕES INTERNACIONAIS DA AMÉRICA LATINA: UM OLHAR ATRAVÉS DOS PARADIGMAS DE INTEGRAÇÃO REGIONAL
}

STRUCTURAL HETEROGENEITY IN LATIN AMERICA'S INTERNATIONAL RELATIONS: A LOOK THROUGH REGIONAL INTEGRATION PARADIGMS

\author{
Leonardo Granato ${ }^{1}$ \\ Ian Rebouças Batista ${ }^{2}$
}

Universidade Federal do Rio Grande do Sul, Rio Grande do Sul, Brasil

\begin{abstract}
Resumo: O presente artigo busca debater a heterogeneidade que historicamente marca as relações internacionais da América Latina tanto no âmbito nacional quanto no âmbito regional. A proposta é trabalhar a referida heterogeneidade como um fator a ser explicado e como um fator explicativo. No que diz respeito à heterogeneidade como fator a ser explicado, buscaremos as causas de tal fator na condição periférica dependente do continente. Com relação à heterogeneidade como fator explicativo, utilizaremos a heterogeneidade para explicar os entraves à integração regional, ao revisitarmos os paradigmas das propostas na região (velho regionalismo, novo regionalismo e regionalismo pós-liberal) e apontarmos a diversidade de interesses, contextos, desafios, em cada período, nos âmbitos nacional, regional e internacional.
\end{abstract}

Palavras-chave: Relações Internacionais; América Latina; Integração Regional.

\begin{abstract}
This paper aims to debate the heterogeneity that, throughout history, has shaped Latin America's international relations in the domestic and regional fields. Our purpose is to convey heterogeneity as a consequence of the peripheral dependent conditions as well as a cause that explains the obstacles faced by regional integration processes, as we revisit the Old Regionalism, New Regionalism and Post-Liberal Regionalism paradigms, exposing the diversity of interests, contexts, challenges, in each period, in the domestic, regional and international fields.
\end{abstract}

Keywords: International Relations; Latin America; Regional Integration.

\footnotetext{
1 Professor do Programa de Pós-Graduação em Ciência Política da UFRGS. Email: granato.leonardo@gmail.com.

2 Mestrando do Programa de Pós-Graduação em Ciência Política da UFRGS. Email: reboucas.ian@gmail.com.
} 


\section{INTRODUÇÃO}

Tradicionalmente, as relações internacionais dos países latino-americanos caracterizaram-se pela heterogeneidade de orientações e posicionamentos, decorrente das diferentes opções assumidas em matéria de modelos políticos (governo, regime), de modelos de desenvolvimento, de estratégias de inserção externa, de agendas bilaterais com os Estados Unidos; em definitivo, da diversidade cultural, social, política e econômica contida em cada história nacional. Tal heterogeneidade tem tido expressão de forma particular nos processos de integração regional, dificultando, até os dias atuais, a alternativa de construir um espaço institucional que possibilitasse unificar a visão estratégica do continente. Esta diversidade ou heterogeneidade estrutural ${ }^{3}$ tem se manifestado, segundo o retratado por Paradiso (2008) e Soares de Lima (2013), como um dos traços marcantes das relações externas da América Latina. Desta forma, o nosso objetivo é discutir, sob a forma de ensaio teórico e por meio de uma pesquisa bibliográfica, a referida heterogeneidade como um fator a ser explicado, bem como um fator explicativo.

Enquanto fator a ser explicado, esta heterogeneidade regional pode ser explicada, pelo menos parcialmente, através da natureza e das especificidades do Estado latino-americano, colonial, periférico, dependente e subdesenvolvido, marcado, na sua caminhada, pela instabilidade política. O próprio O’Donnell já salientava que as crises de governo e de regime formam parte da história "normal" da América Latina (O’DONNELL, 1982, p. 53). Isso, inclusive, é verificado até nossos dias com o fato de que vinte e um presidentes latino-americanos tenham deixado seu cargo antes de tempo entre 1991 e 2016, incluído o impeachment sofrido pela presidenta Dilma Rousseff. Desta forma, refletir sobre a diversidade que subjaz às relações internacionais latinoamericanas contemporâneas nos impõe trazer, em primeiro lugar, uma discussão sobre a evolução histórica do Estado e das instituições políticas no nosso continente.

\footnotetext{
${ }^{3}$ Utilizamos o conceito de heterogeneidade estrutural baseado no entendimento de Ianni (1988) de que são diversas as formas de nação na América Latina, constituindo características de oligarquia, liberalismo, populismo, autoritarismo ou democracia, a depender do jogo das forças sociais internas e externas. Internamente, o autor chama atenção para o papel das elites nacionais, que não representam interesse condizente com a diversidade de classes, culturas e povos que compõem a nação, enquanto que externamente os países latinos se colocam condicionados aos interesses dos países do centro do sistema internacional.
} 
Enquanto fator explicativo, tal heterogeneidade estrutural pode contribuir para entendermos por que, atualmente, praticamente não existe uma organização regional integrada por todos os países latino-americanos, com exceção da Comissão Econômica para América Latina e o Caribe (CEPAL) e da Comunidade de Estados LatinoAmericanos e Caribenhos (CELAC). Essa última, criada em 2010 com o objetivo de articular um espaço de concertação política sem a influência das instituições hemisféricas comandadas pelos Estados Unidos. De igual forma, as diferenças na região também se manifestam nos múltiplos processos de integração vigentes atualmente, que representam esforços diferentes em escopo e objetivos. Sabemos que a integração regional inevitavelmente terá de lidar com Estados de tamanhos e recursos assimétricos (SCHMITTER, 2010), mas as escassas margens de convergência para aprofundar agendas compartilhadas de ação, observadas nos distintos processos contemporâneos, revelam as dificuldades advindas das diferenças naturais de todo e qualquer Estado nacional cujo movimento instintivo é de agir visando à autopreservação e sobrevivência (GRANATO, 2015).

Desta forma, o presente trabalho consistirá em efetuar uma série de considerações sobre as especificidades do Estado na América Latina, bem como em buscar evidenciar a referida heterogeneidade estrutural da política internacional latinoamericana através de um breve percurso da integração regional no continente. Para tanto, adotaremos uma abordagem neomarxista através de autores como Miliband (1972), Poulantzas ([1968] 2007) e O’Donnell (1978), o que nos permitirá analisar as condições e variáveis internas e externas aos Estados, analisando os contextos nacionais, regionais e internacionais para cada momento da integração regional latinoamericana, buscando suprir assim nosso duplo objetivo de explicar a heterogeneidade estrutural dos países latino-americanos e de entendê-la como fator explicativo para os limites dos processos de integração regional na América Latina. Veremos como a heterogeneidade marcará em distintos momentos o mosaico latino-americano, e buscaremos entender o porquê disso, bem como a heterogeneidade será variável explicativa para os limites de diversas propostas de integração regional.

A escolha de estudar esse fenômeno tipicamente latino-americano através dos processos de integração regional se justifica por dois motivos. O primeiro advém da importância do campo da integração regional para os estudos de relações internacionais 
da América do Sul, correspondendo à segunda área mais trabalhada na produção acadêmica da região (MEDEIROS, et al., 2016). O segundo motivo se expressa a partir do momento que a integração regional se apresenta como expressão mais imediata das relações internacionais principalmente para os países periféricos, constituindo-se como horizonte necessário a esses devido ao fato de que quase nenhum país (com exceção dos Estados Unidos, da China, e talvez da Rússia) teria condições de enfrentar isoladamente os impactos do capitalismo global. Já no caso da América Latina em particular, toda política que represente uma escolha das formas de inserção no sistema internacional mostra-se fundamental para combater a percepção da ordem mundial como submetida a uma dinâmica incontrolável, de efeitos inexoráveis, para lutar, em definitivo, contra um suposto estado de "periferismo" permanente (FURTADO, 1968; JAGUARIBE, 1973).

Consequentemente, em um presente marcado pela importância dos processos de integração regional, os regionalismos apresentam-se como um dos vetores mais relevantes para entender e explicar a dinâmica internacional, bem como as realidades nacionais dos Estados envolvidos, tornando artificial a rígida contraposição de fatores externos e internos. Apesar de que os processos de integração, entendidos em termos amplos como processos de reordenamento político-territorial, não constituem uma novidade na história mundial, poderíamos expressar que a novidade está no modo em que os processos integracionistas vêm sendo desenvolvidos a partir da segunda metade do século XX, com acentuada aceleração no último quarto de século, e suas implicações no plano interno dos Estados, bem como no quadro das relações internacionais do continente.

\section{HETEROGENEIDADE: FATOR A SER EXPLICADO}

Como fator a ser explicado, a heterogeneidade estrutural nas relações internacionais dos países latino-americanos pode ser vinculada às especificidades e à evolução do Estado latino-americano no sistema interestatal capitalista.

Ao introduzirmos nossa discussão a partir de uma perspectiva voltada a dialogar com uma perspectiva neomarxista, vemos que o funcionamento da economia do mundo capitalista tem como premissa a existência de uma superestrutura política de Estados soberanos vinculados e legitimados por um sistema interestatal. Cristalizando uma 
geografia discriminatória, este sistema interestatal capitalista se baseou no expansionismo de seus Estados líderes e no impulso conquistador que favoreceu a expansão dos mercados locais para mais além das fronteiras, criando as oportunidades monopólicas para a obtenção de lucros extraordinários. Este processo, que pode ser denominado de "incorporação" de novas áreas à economia-mundo capitalista (WALLERSTEIN, 1979), implicou a reformulação de fronteiras e de estruturas políticas de tais áreas incorporadas, dando lugar à criação de "Estados soberanos", ou, melhor dizendo, "candidatos" a Estados soberanos: as colônias.

Inicialmente, cabe entendermos sob que ótica o Estado será aqui estudado. A visão do neomarxismo estrutural de autores como Nicos Poulantzas ([1968] 2007) e Ralph Miliband (1972) entendem o Estado como reprodutor último do modo de produção capitalista a partir do momento que possui função de regular a sociedade. A visão de Guillermo O’Donnell (1978) é também a de um Estado com fundamental papel nas relações sociais internas, e nos serve para aprofundarmos melhor a função do Estado imbricado nas relações sociais. Para o autor, o Estado seria componente político das relações de dominação existentes em um território determinado. Esta dominação se daria através de dois instrumentos, coerção e ideologia. A principal relação de dominação na sociedade capitalista seria justamente entre o detentor dos meios de produção, empregador, e o trabalhador assalariado, empregado. Nessa relação assimétrica, o trabalhador não possui os meios de produção, por isso depende do empregador, enquanto que este não possui os meios de coerção, para fazer com que o trabalhador lhe obedeça. É nesse momento que surgem as instituições estatais nas relações sociais: leis trabalhistas, ordenamento jurídico, direito à propriedade privada, dinheiro, e assim por diante. O Estado respalda a relação social de exploração do trabalhador, e dessa forma surge como expressão geral de um interesse particular, noção presente também em Poulantzas ([1968] 2007) e Miliband (1972). Essa relação social que o Estado sustenta articula de maneira desigual e contraditória a sociedade (O’DONNELL, 1978), o que não é percebido por todos. Ponto fundamental da dominação ideológica estatal é obscurecer o fato de que determinadas relações sociais, como as descritas acima, são conflituosas. Nesse momento se faz necessária uma dominação ideológica adequada, que para O’Donnell constitui-se na ideia de interesse nacional. 
Na tentativa de obscurecer a relação de dominação imbricada na atuação do Estado sob a sociedade, florescem os símbolos, valores e sentimentos de pertencimento típicos da ideia de nação (OSZLAK, [1978] 2007). Nesse sentido, as condições materiais que tornam possível a conformação de um mercado nacional é condição necessária para a constituição de um Estado nacional (OSZLAK, [1978] 2007). Ou seja, há de se desenvolver a condição básica do capitalismo -o mercado interno- para que se desenvolva o simbolismo nacional, que tem como objetivo o obscurecimento das relações de dominação capitalista respaldadas pelo Estado. Um esquema complexo de se libertar uma vez que se adentra.

Acrescenta-se a isso o fato de que, depois de alcançar a independência, e durante a primeira metade do século XIX, os países latino-americanos, que ainda não constituíam Estados nacionais consolidados, e muito menos um sistema político e econômico regional, foram colocados, com o apoio das elites locais, na periferia da geopolítica mundial, através de uma variedade de tratados comerciais de caráter desigual, que replicavam a relação de subordinação característica do seu passado colonial. Com o passar do tempo, a consolidação das classes ou alianças de classes que controlavam as estruturas produtivas exportadoras destes países precisaria de um sistema político de dominação (o Estado nacional) capaz de consolidar, expandir e reproduzir o novo padrão capitalista de relações sociais, orientado a favorecer o processo de acumulação. A aparição das classes médias e populares na vida política e a ampliação da democracia formal introduziram, no Estado latino-americano, um moderado reformismo na ordem tradicional conservadora modernizante, gerando-se uma situação de permanente conflito social e instabilidade política, marcada pela ruptura da ordem constitucional e por processos ditatoriais, que se manteve durante grande parte do século XX (OLIVER-COSTILLA, 1997; O`DONNELL, 1993; GRACIARENA, 1984; ZAVALETA-MERCADO, 1984; ZERMEÑO, 1981).

Assim, o Estado latino-americano assumiu a tarefa de estruturar as relações sociais capitalistas nos seus territórios, enfrentando os condicionantes externos que o próprio sistema internacional do poder e uma divisão internacional do trabalho favorável aos países centrais lhe impunham. Tradicionalmente, tal tarefa foi assumida com capacidades diferentes pelos países latino-americanos, geralmente condicionados pela atuação da potência hegemônica e de seus interesses. Nesse sentido, importa 
enfatizar que foram os diferentes "modelos" de desenvolvimento e inserção externa (associados à potência hegemônica ou, por outro lado, pretendidamente "autônomos") que constituíram os traços marcantes das relações externas latino-americanas (JAGUARIBE, 1973; FERRER, 2006). Essa divergência de modelos, bem como a própria instabilidade política, decorrente da fragilidade interna e vulnerabilidade externa, remete ao papel "homogeneizador" dos Estados Unidos na região. Durante o período da Guerra Fria, uma falsa "homogeneização regional" foi efetuada pela potência hemisférica através do Tratado Interamericano de Assistência Recíproca (e suas respectivas instituições de difusão da Doutrina de Segurança Nacional), da forte presença de empresas multinacionais, e da própria Organização de Estados Americanos (OEA), cuja função sempre foi sobretudo política e cuja agenda refletia majoritariamente os interesses norte-americanos (KAPLAN, 1969; O'DONNELL; LINCK, 1973; SOARES DE LIMA, 2013).

Por sua vez, nos anos 90, a América Latina foi levada a uma nova "homogeneização forçada" por via do ajuste estrutural e das condicionalidades impostas nas respectivas negociações da dívida externa, destacando-se as dez propostas de reforma econômica do chamado "Consenso de Washington", cuja contrapartida era a construção do Estado neoliberal na América Latina, bem como a construção do projeto neocolonizador da Área de Livre Comércio para as Américas (ALCA). Nos últimos quinze anos, após a "virada à esquerda" dos países da região, essa heterogeneidade por nós argumentada se materializou na adesão dos países latino-americanos a projetos regionais diversos, bem como nas diferentes diretrizes nacionais em matéria de política externa e desenvolvimento (SARTI, 2014; SOARES DE LIMA, 2013; FIORI, 2009).

Em suma, esta heterogeneidade estrutural da própria natureza dos Estados latinoamericanos, e da sua posição no sistema interestatal capitalista, nos remete ao debate atual sobre a natureza e o alcance da globalização (FERRER, 2006; RAPOPORT, 1997; IANNI, 1988), que por sua vez se refere ao mesmo problema histórico sobre como os países latino-americanos, atrasados, resolvem o "dilema" de seu desenvolvimento e inserção em um sistema internacional articulado em torno das estruturas hegemônicas de poder. Vejamos, então, como a heterogeneidade expressou-se nos processos de integração regional em particular. 


\section{HETEROGENEIDADE: FATOR EXPLICATIVO}

Enquanto fator explicativo, a referida heterogeneidade pode contribuir para explicar as dificuldades, experimentadas pelos países latino-americanos, em articular instâncias político-institucionais capazes de unificar a visão estratégica do continente, principalmente no que diz respeito aos ideais de autonomia e desenvolvimento. Para tanto, é importante arquivar o argumento teleológico decorrente da adoção de um modelo idealizado da União Europeia (SOARES DE LIMA, 2013), e pensarmos nos desafios a serem enfrentados pelos processos de integração na América Latina, enquanto expressão das relações externas de seus países, marcadas pela heterogeneidade de visões e perspectivas de distinta índole.

Existe um consenso na literatura a respeito do fato de que a integração latinoamericana experimentou três grandes momentos ao longo da segunda metade do século $\mathrm{XX}$ até a atualidade; um primeiro momento ${ }^{4}$, geralmente conhecido como o "velho regionalismo", que abarca o período que vai desde o começo dos anos 60 até meados da década de 80; um segundo momento, o do "novo regionalismo", que terá lugar ao longo dos anos 90 e coincidirá com a hegemonia do pensamento neoliberal; e um terceiro momento, o do "regionalismo pós-liberal", ou pós-hegemônico (VEIGA; RIOS, 2007; RIGGIROZZI; TUSSIE, 2012) no século XXI.

$\mathrm{Na}$ época do velho regionalismo, as iniciativas de integração no continente estiveram informadas pelas políticas cepalinas desenvolvimentistas, e, ainda que não tenham sido bem-sucedidas, apresentavam forte componente autonômico ao criar um espaço na região sem a presença dos Estados Unidos, país esse que deixou de propor qualquer iniciativa de integração regional à época uma vez que sua prioridade era a liberalização comercial no plano multilateral (JAGUARIBE, 1973; KAPLAN, 1969).

Fatores como a deterioração dos termos de troca no comércio internacional estimularam, a partir da década de 50, um grupo de países latino-americanos a dar início a um processo de integração econômica, não com vias de estabelecer uma união política, mas sim como um meio em direção ao desenvolvimento interno de cada um deles. Ainda que a primeira experiência integracionista da CEPAL tenha sido a do

\footnotetext{
${ }^{4}$ Não que as primeiras propostas tenham apenas surgido na década de 1960. Barnabé (2012) indica que desde o início do século XX o eixo ABC (Argentina, Brasil e Chile) assinaram tratados que visavam a cooperação regional.
} 
Mercado Comum Centro-Americano, quase simultaneamente seria gerado um projeto ainda mais ambicioso, que consistia na integração do conjunto da América Latina, ideia que veio sendo amadurecida desde a década de 40, com a primeira tentativa de integração econômica entre Argentina e Brasil (GRANATO, 2015).

Cumpridas as negociações, em 1960 seria originada a Associação LatinoAmericana de Livre Comércio (ALALC), com o objetivo de criar, em um prazo máximo de doze anos, uma zona de livre comércio, que avançaria até a criação de um mercado comum, que criaria estímulos para o desenvolvimento industrial sobre bases competitivas, reduzindo a dependência externa dos países membros frente ao resto do mundo. Simbolicamente, a iniciativa ALALC significou um hiato histórico, ao propor um objetivo de "unidade regional" visando à superação de um longo ciclo de desencontros e fragmentação (KAPLAN, 1969). Entretanto, a iniciativa fracassaria como consequência da própria diversidade de orientações na política interna e externa dos países membros e da baixa interdependência (o caráter competitivo dos países, as tendências ao protecionismo comercial e a competição estratégico-militar em nível subregional), das grandes assimetrias e desigualdades nacionais e sociais dentro de cada país, e do bloco como um todo, bem como da forte ingerência das empresas multinacionais, que levou Jaguaribe (1973) a qualificar essa integração de "satelizada", em contraste com seu "modelo autônomo de desenvolvimento e integração".

Enquanto processo que visava à união de todos os países latino-americanos, a ALALC não conseguiu obter condições estáveis e apropriadas para um desenvolvimento dos países da região em condições de igualdade e autonomia. Algumas razões internas à região podem ser elencadas como responsáveis pela não evolução do bloco, como a instabilidade interna dos países da região, a falta de uma visão compartilhada de coordenação de políticas e a falta de coincidência de objetivos comuns (SÖDERBAUM, 2016). Frente à impossibilidade na consolidação da ALALC, os países membros decidiram avançar em projetos menos ambiciosos, de modo a criarem o sistema de consulta e coordenação em matéria econômica, o Sistema Econômico Latino-Americano (SELA), em 1975, e a Associação Latino-Americana de Integração (ALADI), em 1980. Ainda que, com esta última organização, o objetivo final seguisse sendo a constituição de um mercado comum, desta vez não se pretendia abarcar todo o universo alfandegário, sendo isso possibilitado a partir de acordos de 
complementação econômica de caráter reduzido (GRANATO; ODDONE, 2008). Assim, tornou-se possível a coexistência de processos de integração de diferentes composições, alcances e objetivos, o que reflete, mais uma vez, a heterogeneidade estrutural argumentada.

Vinculados ao período de crise e recessão que afrontaram os países latinoamericanos nos anos 1980, os resultados deste exercício seguiram sendo demasiadamente modestos, com escassos efeitos tanto em termos quantitativos (incremento do comércio regional), como em relação ao objetivo de integrar as economias da região e induzir um processo de especialização intrassetorial. Em uma tentativa de explicar os limites das propostas de integração desse período, Castro e Malamud (2007) elaboraram um quadro com os contextos políticos e econômicos de então, reproduzido no Quadro 1. Este esforço dos referidos autores se aproxima do nosso objetivo de discriminar os âmbitos nacionais, regionais e internacionais em cada período de integração abordado no presente trabalho. Indicaremos similar quadro para cada momento da integração regional latino-americana.

Quadro 1 - Velho regionalismo (1960-1980)

\begin{tabular}{|c|c|c|}
\hline & Contexto Político & Contexto Econômico \\
\hline Âmbito Doméstico & Instabilidade democrática & $\begin{array}{c}\text { Subdesenvolvimento e políticas } \\
\text { zig-zag }\end{array}$ \\
\hline Âmbito Regional & Ausência de objetivos comuns & $\begin{array}{c}{ }^{5} \\
\text { Baixa interdependência entre os } \\
\text { países latinos }\end{array}$ \\
\hline Âmbito Internacional $^{7}$ & $\begin{array}{c}\text { Guerra Fria e periferia na } \\
\text { tentativa de imprimir uma } \\
\text { Terceira Via }\end{array}$ & $\begin{array}{c}\text { Deterioração dos termos de troca } \\
\text { no comércio internacional }\end{array}$ \\
\hline
\end{tabular}

Fonte: Retirado, traduzido e adaptado de Castro e Malamud (2007).

\footnotetext{
${ }^{5}$ Falta de continuidade de políticas à longo prazo.

${ }^{6}$ No quadro original: "Institucionalidade inadequada". Segundo os autores, o referido termo refere-se à principal nuance histórica desses processos: o intergovernamentalismo (CASTRO; MALAMUD, 2007). Neste trabalho, seguindo o argumento de Soares de Lima (2013) com relação às limitações emergentes da adoção do modelo europeu como parâmetro para a avaliação da integração latino-americana, optamos por substituir a causa da "institucionalidade inadequada" pela causa da "ausência de objetivos comuns" que, a nosso modo de ver, explica de forma mais precisa o fracasso da integração nesse período, sem recorrer ao argumento teleológico da experiência europeia com capacidade de reprodução para outras regiões do mundo.

${ }^{7}$ Incremento nosso ao quadro original. Schmitter (2010) aponta que processos de integração regional podem ser vulneráveis a fatores exógenos de modo crítico. Por mais que o autor parta do modelo europeu, podemos trabalhar com essa noção se contextualizamos a América Latina na condição de dependente diante do hegemon hemisférico (FURTADO, 1968; CARDOSO; FALETTO, 1973).
} 
Apesar da heterogeneidade em termos de modelos de desenvolvimento, de desempenho interno e de perspectivas e interesses em torno da integração regional, estas experiências constituem valiosos antecedentes no que diz respeito ao esforço de criar vontades políticas em torno de um objetivo comum, superador de interesses e visões poucas vezes convergentes, o que caracteriza a condição básica para impulsar um processo associativo deste tipo.

No momento seguinte, com o fim da Guerra Fria, os processos de integração vão convergir sob a liderança dos Estados Unidos e a ascensão do neoliberalismo na América Latina, expressa no já mencionado Consenso de Washington. Neste contexto, o novo ciclo de regionalismos, representado principalmente pela criação do Tratado de Livre Comércio da América do Norte (e a "rejeição" do México do legado de resistência anti-hegemônico), pela constituição do Mercado Comum do Sul (Mercosul) (sobre a base dos acordos pioneiros da Argentina e Brasil), pelo relançamento do Pacto Andino de 1969 (reconfigurado na Comunidade Andina) e pela proposta não concluída da ALCA, contribuiria com a disseminação de processos associativos que adotaram um modelo de integração com abertura para os mercados externos, que assumiria um caráter principalmente comercial (GRANATO, 2015). O referido modelo fazia parte do que, em 1994, a CEPAL definiu como o que deveria ser a "nova" estratégia de integração regional no mundo: o "regionalismo aberto", processo que surge ao se conciliar a interdependência nascida dos acordos especiais de caráter preferencial e aquela impulsionada basicamente pelos sinais do mercado resultantes da liberalização comercial em geral (CEPAL, 1994).

Um papel similar ao da CEPAL foi exercido pelo Banco Interamericano de Desenvolvimento (BID), em defesa do "novo regionalismo" e sua complementaridade com o multilateralismo, no sentido de completar e reforçar a liberalização unilateral, bem como a multilateral, empreendidas como parte do processo de reforma estrutural dos Estados latino-americanos (BID, 2002). Desta forma, os esquemas integracionistas, sobre os quais seria desenvolvido o novo regionalismo latino-americano, simbolizariam a hegemonia do programa neoliberal na agenda regional. Uma característica desse momento é a importância renovada das instituições hemisféricas, particularmente da Organização dos Estados Americanos (OEA), com a promulgação da Carta Democrática, que assinalava a convergência em torno das democracias de mercado. Se 
o velho regionalismo havia significado, em algum sentido, a tentativa dos países latinoamericanos de fortalecer regionalmente os processos autônomos de industrialização e inserção externa, a opção institucional por um esquema de regionalismo aberto deveria servir ao objetivo de reforçar os processos de reforma estrutural dos mercados domésticos, "unificar" os processos políticos internos sob o princípio liberaldemocrático, e favorecer a inserção das economias latino-americanas nas cadeias globais de valor.

Para Weyland (2004), os impactos do neoliberalismo na região são ambíguos: há fortalecimento da democracia nos países da região, mas redução de sua qualidade. Isso decorreu uma vez que os países da região se abriram para as pressões internacionais de preservação da democracia (o que fortalece a opção pelo regime democrático recém reestabelecido pós-governos autoritários), gerando, ao mesmo tempo, fortalecimento das elites econômicas e enfraquecimento de partidos de esquerda e movimentos sociais, enfraquecendo, assim, a participação social na política e redução dos processos de accountability. A abertura ao mercado internacional também enfraqueceu a qualidade das democracias latino-americanas ao limitar o escopo da escolha democrática, uma vez que se atrela a constrangimentos econômicos externos (WEYLAND, 2004). Em outras palavras, durante a década de 1990, principalmente, uma vez atrelados aos ditames de organismos internacionais como o Fundo Monetário Internacional e o Banco Mundial, os países latino-americanos possuíam reduzida margem de manobra para formular, democraticamente, suas políticas econômicas.

Os esquemas integracionistas latino-americanos avançariam, no contexto do regionalismo aberto e da proposta hemisférica de constituir a ALCA, a partir de uma agenda de "integração negativa" centrada na eliminação progressiva das barreiras ao comércio entre os países membros. Ainda que o resultado viesse a ser o incremento nos intercâmbios comerciais, os avanços dos diferentes processos de integração durante a década de 1990 foram debilitados pela alta vulnerabilidade externa das economias da região frente às crises financeiras internacionais que ocorreram desde meados dessa década.

Além disso, estes novos esquemas associativos careceram de uma agenda de "integração positiva" que impulsionasse políticas comuns em áreas estratégicas, tais como infraestrutura, energia, transporte, coordenação macroeconômica, política social e 
construção de instituições comuns, dentre outros, agenda essa que levaria à profundidade política, social e territorial às referidas iniciativas de integração. Por tais motivos, até o fim da década de 1990, os processos de integração pareciam perder impulso, questão essa que seria aprofundada sob o ciclo do estancamento econômico, da mobilização social e da instabilidade política que afetou vários países da região (GRANATO, 2015).

Ao analisar a primeira década de funcionamento do Mercosul, Malamud (2005) indicou que o bloco possui baixo grau de institucionalização, concentrando o poder de agenda e o processo decisório em cúpulas presidenciais, o que acarreta reduzida participação de outros atores sociais relevantes. Dada essa característica, o autor coloca

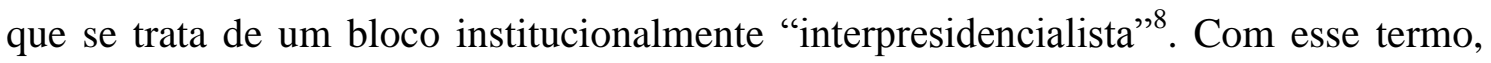
buscou articular a ideia de que os presidentes dos países membros do bloco estão acima de quaisquer outros atores regionais ou domésticos e controlam os rumos do processo de integração regional. Contudo, o autor não vai entender isso como algo negativo. Malamud (2005) aponta que os presidentes são munidos de capacidades institucionais estatais, como vetos e decretos, possuem legitimidade popular e que suas capacidades constitucionais garantem o cumprimento das políticas acordadas no âmbito regional. Ziccardi (2015) concorda com esse argumento e indica que a principal estrutura institucional dos processos de regionalização da América Latina é o presidencialismo. Castro e Malamud (2007) inclusive identificam o novo regionalismo como sendo limitadamente bem-sucedido devido a esse fator interpresidencialista. Para os autores, o progresso desse modelo se deu por questões políticas, e não econômicas. Ao analisar o Quadro 1, que discrimina os contextos nacionais e regionais do velho regionalismo, entende-se que o desenvolvimento do caráter presidencialista à época do novo regionalismo superou em partes dois entraves políticos de outrora: alcançou-se estabilidade democrática, como exposto por Weyland (2004), e garantiu uma adequada institucionalização ${ }^{9}$, o presidencialismo, como defendido por Ziccardi (2015). É

\footnotetext{
${ }^{8}$ Tal qual exposto por Malamud (2005), com este termo busca-se uma denominação própria do intergovernamentalismo observado nos processos de integração regional da América Latina. A ideia é unir em um só termo o caráter presidencialista, típico dos países da região e observado tanto nas políticas internas quanto externas, e o caráter intergovernamental dos processos regionalistas.

${ }^{9}$ Como exposto na nota 4, Castro e Malamud (2007), ao elaborarem a versão original do Quadro 1, indicavam "Institucionalismo Inadequado" no âmbito regional como entrave para o sucesso dos processos típicos do velho regionalismo, característica modificada por nós na nossa versão do Quadro 1, pelas razões já indicadas na mencionada nota.
} 
possível elaborar, portanto, uma tabela similar para o novo regionalismo, como demonstra o Quadro 2.

Quadro 2 - Novo regionalismo (1980-2000).

\begin{tabular}{|c|c|c|}
\hline Âmbito Doméstico & Contexto Político & Contexto Econômico \\
\hline Âmbito Regional & $\begin{array}{c}\text { Fortalecimento da democracia / } \\
\text { Redução de sua qualidade }\end{array}$ & $\begin{array}{c}\text { Instabilidade econômica e } \\
\text { instabilidade de políticas } \\
\text { econômicas }\end{array}$ \\
\hline Antergovernamentalismo & $\begin{array}{c}\text { Incremento nos intercâmbios } \\
\text { comerciais / Vulnerabilidade } \\
\text { externa das economias da região }\end{array}$ \\
\hline Âmbito Internacional & Hegemonia global dos Estados & Consenso de Washington \\
\hline
\end{tabular}

Fonte: Elaboração nossa.

Como se pode notar, por mais que parcialmente mais positivos os contextos políticos nacionais, regional e internacional, os contextos econômicos não eram favoráveis aos países latino-americanos e à região, o que ainda se apresentava como barreiras aos processos de integração.

No início do novo milênio, a ordem neoliberal demonstrou sua incapacidade de gerar um desenvolvimento integral nos países da região, o que ficou evidenciado na falência de seus respectivos indicadores econômicos e sociais. As políticas neoliberais na América Latina geraram sua própria resistência (o que cristalizou ainda mais a heterogeneidade característica da região em geral) e grandes setores da população elegeram democraticamente forças políticas de esquerda e centro-esquerda que propugnavam a necessidade de buscar alternativas a este modelo de exclusão e desigualdade. Em outras palavras, este processo de mudança de orientação política e ideológica foi resultado das mobilizações sociais e dos processos eleitorais que questionaram os ditames neoliberais, ao mesmo tempo em que, com vistas a construir projetos alternativos, propuseram, em linhas gerais, revitalizar o papel do Estado como regulador da economia, promotor do desenvolvimento e distribuidor de bem-estar social ao setor majoritário da população.

A nova configuração política se expressou não somente na diversidade das experiências nacionais, mas também, dentre outros fatores, na participação dos Estados em diferentes processos de integração regional e de concertação política, baseados,

\footnotetext{
${ }^{10}$ Baseado em Brasil e Argentina.
} 
também, em diversas concepções, objetivos e interesses. Assim, o novo modelo de regionalismo de base social e com aspirações de desenvolvimento e autonomia (GRANATO, 2015), vinculado a uma crítica ampla ao paradigma neoliberal da década passada, emergiu de projetos bastante heterogêneos, tais como o Mercosul "reconfigurado" sob liderança dos governos kirchneristas e petistas; a Aliança Bolivariana para os Povos da América Latina-Tratado de Comércio dos Povos (ALBATCP), sob liderança da Venezuela (e com expressivo apoio de vários países centroamericanos); a União de Nações Sul-Americanas (UNASUL) e a já mencionada CELAC, concebidos no intuito de caminhar para uma visão política e estratégica da integração regional. É importante salientar que o caráter contra-hegemônico desses projetos de integração manifestou-se frente à decisão comum de "romper" com o esquema de integração assimétrica proposta pela ALCA, promovido pela potência hemisférica (ODDONE; GRANATO, 2009).

Como apontam Granato, Oddone e Battaglia (2016), essas propostas integracionistas típicas dos governos de centro-esquerda vão se aproximar, ao menos enquanto proposta ou discurso, as noções de autonomia e desenvolvimento presentes em autores como Puig e Jaguaribe. O MERCOSUL reconstituído, para os autores, seria um exemplo da autonomia heterodoxa que escreve Puig, que significa perseguir desenvolvimento interno ao mesmo tempo que possuem discrepâncias de interesses, e se vincular internacionalmente com outros atores ao mesmo tempo que não rompe com a potência hemisférica (PUIG, 1980; 1984).

Por sua vez, a UNASUL é identificada como próximo ao modelo autônomo de desenvolvimento e integração proposto por Jaguaribe (1973) e ao conceito de integração integral de Puig (1986). Para Granato, Oddone e Battaglia (2016), a UNASUL aparenta buscar o desenvolvimento de cada país membro através da maximização nacional e regional da autonomia e da maximização de recursos e mercados, o que possibilita crescente capacidade independente de segurança nacional e regional. Em seu Tratado Constitutivo, a organização esclarece que buscará a integração cultural, social, econômica e política, o que revela o caráter integral da integração almejada, e baseando-se em valores democráticos e de respeito à soberania das nações sul-americanas, refletindo uma noção de defesa da autonomia dos povos sulamericanos. 
Já o modelo de integração proposto pela ALBA-TCP representa a autonomia secessionista da qual escreveu Puig, o que significa romper com a potência hemisférica através de seus projetos "Gran-Nacionais" que visam "unir capacidades e forças na perspectiva de produzir transformações estruturais e desenvolvimento integral para existência de nações soberanas e justas" (GRANATO; ODDONE; BATTAGLIA, 2016, p.167) ${ }^{11}$. Além disso, a ALBA-TCP carrega em seu tratado constitutivo os pilares ideias da integração latino-americana tal qual sugeriu Puig: solidariedade, cooperação e complementariedade. A ALBA-TCP se diferencia dos demais modelos de integração pós ou contra-hegemônicos por representar, ao menos discursivamente, um secessionismo mais radical $^{12}$ em relação a potência hemisférica norte-americana, típica do "socialismo do século XXI" presente no governo de Hugo Chávez (MUHR, 2010; 2011).

Por fim, a CELAC é entendida por Granato, Oddone e Battaglia (2016, p.169) como uma "ferramenta para adquirir relativa estabilidade pela via da autonomia", se aproximando da noção de "visão ampla" da integração da qual versava Puig. Contudo, não é organismo regional como os demais aqui trabalhados, configurando-se apenas como reunião presidencial bianual. O grande valor dessa iniciativa, de 2008, é a não presença dos EUA nessa cúpula que reúne todos os demais países do hemisfério americano.

Dessa forma, podemos traçar o Quadro 3, correspondente às conjunturas nacionais, regionais e internacionais desse recente período da integração regional.

Quadro 3 - Regionalismo pós-liberal (2000-2015).

\begin{tabular}{|c|c|c|}
\hline & Contexto Político & Contexto Econômico \\
\hline Âmbito Doméstico ${ }^{13}$ & $\begin{array}{c}\text { Governos de centro-esquerda } \\
\text { com pautas de redistribuição de } \\
\text { renda e inclusão social }\end{array}$ & $\begin{array}{c}\text { Crescimento econômico ou } \\
\text { estabilidade econômica }\end{array}$ \\
\hline Âmbito Regional & $\begin{array}{c}\text { Múltiplas propostas de } \\
\text { integração regional baseadas em } \\
\text { noções distintas de autonomia }\end{array}$ & $\begin{array}{c}\text { Alta do preço das commodities } \\
\text { favorecendo a região }\end{array}$ \\
\hline Âmbito Internacional & $\begin{array}{c}\text { Estados Unidos voltados para a } \\
\text { Guerra ao Terror se afasta da }\end{array}$ & $\begin{array}{c}\text { Ascensão de Potências } \\
\text { economicamente emergentes }\end{array}$ \\
\hline
\end{tabular}

${ }^{11}$ Tradução livre dos autores.

12 Baseado no entendimento de Weyland et al. (2010) de que Venezuela e Bolívia, dos governos de Chávez e Morales, representariam a esquerda radical da América Latina, em oposição a esquerda moderada de Lula, no Brasil, e de Bachelet, no Chile.

${ }^{13}$ Baseado em Brasil e Argentina. 
\begin{tabular}{|l|c|c|}
\hline & $\begin{array}{c}\text { América Latina / Crescimento da } \\
\text { presença chinesa }\end{array}$ \\
\hline
\end{tabular}

Fonte: Elaboração dos autores.

Esse quadro permite identificar, ao compararmos com os quadros anteriores, que a região nunca experimentou conjuntura tão favorável, no que diz respeito a convergência de interesses para a integração regional, como a da primeira década dos anos 2000. Contudo, a heterogeneidade entre os governos de centro-esquerda e entre os de centro-direita permaneceu emperrando profunda integração. A diversidade de propostas de integração voltadas para o político, social e cultural, representou os múltiplos e conflitantes interesses pela liderança da região.

Para Muhr (2010; 2011), a Venezuela cria e lidera a ALBA-TCP para indicar liderança no norte do continente e na América Central, liderança essa inclusive legitimada pela superioridade relativa de recursos, materiais e institucionais, que a Venezuela possuía em relação aos demais membros do bloco. Riggirozzi e Tussie (2012) apontam inclusive que o bloco é dependente tanto da figura de Hugo Chávez quanto do petróleo Venezuela - dependência que se provou com o passar dos anos, com o fim do governo Chávez e com a crise econômica venezuelana. Já a criação da UNASUL, encabeçada por Argentina, Brasil e Venezuela, revela os distintos interesses estratégicos que cada um desses países possuía para o bloco e suas respectivas inserções regionais (BARNABÉ, 2012), a saber, respectivamente: interesse argentino na integração regional como instrumento de desenvolvimento nacional (GRANATO, 2016); o enfoque brasileiro no âmbito sul-americano como prioridade de sua política externa (BRASIL, 2004); e ampliação do discurso anti-estadunidense bolivariano chavista para a América do Sul, para além da ALBA (GIACALONE, 2005).

Notam-se, dessa forma, distintas visões e interesses para os processos póshegemônicos criados na primeira década do séc. XXI. Além disso, dois pontos podem ser levantados para indicar o não-avanço desses recém-criados organismos: (i) a integração regional na América Latina manteve seu viés intergovernamental, dificultando a permanência dessas políticas para além dos mandatos dos presidentes que as incentivam; (ii) a existência de um abismo entre expectativas, discurso e realidade ${ }^{14}$ (CARMO, 2013).

\footnotetext{
${ }^{14}$ Granato (2016) comprova isso no que diz respeito a ampliação da pauta do Mercosul, chamado pela própria instituição de "Mercosul produtivo e social" durante a primeira década dos anos 2000. O autor
} 
Se dentre os governos de centro-esquerda do período existiam divergências ${ }^{15}$ quanto aos termos de uma integração social, política e cultura, as propostas de integração comercial dos governos de centro-direita acrescentam maior heterogeneidade ao cenário latino-americano dos anos 2000. Criada em 2012, a Aliança do Pacífico une Chile, Colômbia, México e Peru numa proposta de livre circulação de bens, serviços, capitais e pessoas em pleno "momento pós-hegemônico" para a integração regional da região. (BATISTA; BARNABÉ, 2016). Dentre os objetivos do bloco, a expansão e aproximação com o mercado do leste asiático é prioridade, o que revela o caráter estratégico da Aliança que possui mais de trinta países observadores, dentre eles Estados Unidos e China, grandes potências que possuem capacidades de afetar a integração regional latino-americana, seja com tratados bilaterais com os mais distintos países da região, seja institucionalmente, através da aproximação com a própria Aliança, por exemplo.

No que diz respeito a influência dessas potências externas na integração latinoamericana, elas afetam as agendas nacionais, interesses de elites e visões de política externa dos países da região, o que, nos termos de Fiori (2008), fazem parte de um processo mais amplo que envolve a competição interestatal global.

No caso dos Estados Unidos, a partir de uma rede de acordos bilaterais de livre comércio, a potência estadunidense buscaria configurar um "arranjo de integração aberta" na região latino-americana que deslocasse a importância daquelas iniciativas de integração desafiantes dos moldes do regionalismo aberto, abrindo espaço para a projeção e a manutenção de sua hegemonia hemisférica. Já no novo governo Trump, essa estratégia parece estar sendo reformulada. Por sua vez, a China, focada na busca por acesso a recursos naturais e na expansão de mercado para seus bens acabados, ganharia crescente participação no comércio e nos investimentos da região, e reforçaria a inserção econômica dos países latino-americanos baseada na exportação de

aponta descompasso entre o discurso de democratização e participação popular vinculado a criação do Parlamento do Mercosul, do Fórum Consultivo de Estados Federados, Províncias e Departamentos do Mercosul e da Unidade de Participação Social do Mercosul, enquanto que na realidade apenas obtiveram status consultivo, não acarretando, portanto, em efetiva democratização da formulação da pauta do bloco.

${ }^{15}$ Devemos deixar claro que existiram distintas esquerdas no período, que é comumente tratado como homogêneo ou coesos. Valencia (2010) os divide entre governos transformadores (Chávez na Venezuela, Morales na Bolívia, Correa no Equador), reformadores (Lula no Brasil, Kirchner na Argentina, Vázquez no Uruguai) e modernizadores (Bachelet no Chile). Já Weyland et al. (2010) trabalha com os conceitos de esquerda radical, ou contestatória, para o caso venezuelano e boliviano, e esquerda moderada, para o caso de Brasil e Chile. 
commodities, e consequentemente, na desintegração de suas economias cada vez mais voltadas para fora (PADULA, 2013). Como apontam Carmo e Pecequilo (2016), a China se torna primeira ou segunda parceira econômica, tanto em exportação quanto em importação, de diversos países na região, como Argentina, Brasil, Chile, Colômbia e Venezuela - o que inclui parceiros históricos dos Estados Unidos, como Chile e Colômbia. Esse crescimento chinês na região, que data do início do milênio, contribui inclusive para o crescimento econômico da região, visto que a China é grande compradora das commodities latino-americanas (CARMO; PECEQUILO, 2016).

\section{CONCLUSÃO}

Após o exposto, nota-se que a heterogeneidade é marca histórica da região. Neste trabalho, podemos apresenta-la de dois modos: como fator a ser explicado e como fato explicativo. No primeiro momento, contextualizamos a condição periférica na qual o continente latino-americano encontra-se inserido: no sistema internacional hierárquico, onde os Estados são reprodutores ultima ratio do modo de produção capitalista, os Estados periféricos ainda são compostos por elites que se beneficiam dessa condição periférica e, por isso, reproduzem o subdesenvolvimento e a dependência. É nesse contexto que são formados os Estados nacionais latinoamericanos, como forma de dominação de classe que se respalda em símbolos e valores teoricamente compartilhados para que se construa um mercado nacional, de forma que estes Estados possam adentrar ao sistema capitalista.

No segundo momento, buscamos através da análise dos principais períodos históricos da integração regional na América Latina entender a heterogeneidade como fator explicativo para os insucessos de seguidas propostas de integração. Dessa forma, revisitamos o velho regionalismo (1960-1980), o novo regionalismo (1980-1990) e o regionalismo pós-liberal (2000-2015), indicando os contextos nacionais, regional e internacional como fontes que nos permitiram observar heterogeneidade.

Perante uma nova virada conservadora na região, as diferentes opções políticas e orientações estratégicas dos governos parecem ter impactado na reconfiguração dos processos de integração com objetivos autonômicos, agora mais voltados para projetos de inserção e desenvolvimento associados aos centros hegemônicos de poder, e na perda 
de impulso da UNASUL e da CELAC. Por sua vez, apesar da retirada dos Estados Unidos do projeto, países como México e Peru já se mostraram alinhados às políticas aperturistas da Parceria Trans-Pacífico. A vitória de Maurício Macri na Argentina, a assunção do governo de Michel Temer no Brasil, as derrotas nas eleições legislativas e tensões enfrentadas pelo governo Maduro na Venezuela, e o referendum que proibiu um terceiro mandato do presidente Evo Morales na Bolívia, são alguns dos indicadores de um panorama político que, caracterizado por processos de instabilidade internos e pela ausência de bases de sustentação social, já está tendo grande impacto nas relações internacionais desses países, marcadas pela heterogeneidade estrutural e pela falta de, nos termos de Puig (1986), uma genuína política compartilhada de solidariedade estratégica fortalecedora das capacidades nacionais.

Nesse novo momento de reconfiguração de perspectivas para a região, tenhamos em mente a necessidade da análise da conjunta dos distintos âmbitos, nacional, regional e internacional para um adequado desenho de possibilidades. Dada suas condições periféricas, a América Latina necessitaria que os três níveis apresentassem oportunidades para o desenvolvimento dos processos de integração regional. A condição que se manterá será a tendência histórica da heterogeneidade latino-americana, variável independente para qualquer que seja o cenário futuro.

\section{REFERÊNCIAS}

BARNABÉ, Israel Roberto. Del ABC al ABV: El eje Argentina, Brasil y Venezuela em la integración regional en la América del Sur. Cuadernos sobre Relaciones Internacionales, Regionalismo y Desarrollo, v. 07, n. 14, jul./dic. 2012.

BATISTA, Ian R., BARNABÉ, Israel R. Chile, México e a questão da liderança na Aliança do Pacífico. Disponível em: http://voxmagister.com.br/2016/06/01/chilemexico-e-a-questao-da-lideranca-na-alianca-do-pacifico. Acesso em 25 de outubro de 2017.

BID. Más allá de las fronteras: el nuevo regionalismo en América Latina. Buenos Aires: BID, 2002. 
Leonardo Granato

Ian Rebouças Batista
Cadernos Prolam/USP, v.16, n.31, p.5-29, jul./dez.2017

DOI: 10.11606/issn.1676-6288.prolam.2017.133966

BRASIL [MPOG]. Plano Plurianual 2004-2007, 2004. Disponível em: http://www.planejamento.gov.br/assuntos/planeja/plano-plurianual/ppas-anteriores.

Acesso em 10 de outubro de 2017.

CARDOSO, Fernando Henrique; FALETTO, Enzo. Dependência e Desenvolvimento na América Latina: Ensaio de interpretação sociológica. Rio de Janeiro: Zahar, 1973.

CARMO, Corival Alves do. A América do Sul, a China e as contradições da política econômica externa do Brasil. In: CARMO, Corival Alves do et al. (Orgs.). Relações Internacionais: Olhares Cruzados. Brasília: FUNAG, 2014, p. 129-162.

; PECEQUILO, Cristina Soreanu. Brazil and the regional leadership vacuum: the chinese-american advance (2011/2016). Austral: Brazilian Journal of Strategy \& International Relations, v. 05, n. 09, p. 53-73, jan./jun. 2016.

CASTRO, Pablo; MALAMUD, Andrés. Are Regional Blocs Leading from Nation States to Global Governance? A Skeptical Vision from Latin America. Iberoamericana, Nordic Journal of Latin American and Caribbean Studies, v. XXXVII, n. 01, p. 115134, 2007.

CEPAL. El regionalismo abierto en América Latina y el Caribe. La integración económica en servicio de la transformación productiva con equidad, n. 39. Santiago de Chile: CEPAL, 1994.

FERRER, Aldo. Hechos y ficciones de la globalización: Argentina y el Mercosur en el sistema internacional. Buenos Aires: Fondo de Cultura Económica, 2006.

FIORI, José Luis. Estados Unidos, América do Sul e Brasil: seis tópicos para uma discussão. Diplomacia, Estratégia e Política, n. 9, p. 35-44, jan./mar. 2009.

O sistema interestatal capitalista no início do século XXI. In: FIORI, José L.;

MEDEIROS, Carlos; SERRANO, Franklin. $O$ mito do colapso do poder americano. Rio de Janeiro: Record, 2008, p. 11-70.

FURTADO, Celso. Subdesenvolvimento e estagnação na América Latina. Rio de Janeiro: Civilização Brasileira, 1968. 
GIACALONE, Rita. La Comunidad Sudamericana de Naciones: ¿una alianza entre izquierda y empresarios? Nueva Sociedad, n. 202, p. 74-86, 2005.

GRACIARENA, Jorge. El Estado latinoamericano en perspectiva. Figuras, crisis, prospectiva. Pensamiento Iberoamericano, n. 5, p. 39-74, 1984.

GRANATO, Leonardo. Brasil, Argentina e os rumos da integração: o Mercosul e a Unasul. Curitiba: Appris, 2015.

Ideales y estrategias em la periferia del capitalismo. In: RACOVSCHIK, María A.; RAIMUNDI, Carlos (Orgs.). Documento de Trabajo Nro. 4 ¿Fin de ciclo o paréntesis en la región? Balance de la última década y reflexiones sobre el nuevo escenario del MERCOSUR. Buenos Aires: FLACSO Argentina, 2016, p. 77-92.

; ODDONE, Nahuel; BATTAGLIA, Matías. Teoría de la Autonomía: ¿Aún vigente para analizar los procesos de cooperación y de integración en América Latina? Teoria \& Pesquisa: Revista de Ciência Política, v. 25, n. 01, p. 153-175, 2016.

; ODDONE, Nahuel. El sistema internacional y la integración económica regional. In: DURÁN, María Susana et al. (Coords.). Regionalismo y globalización: procesos de integración comparados. Buenos Aires: Editorial UAI, 2008, p. 17-35.

IANNI, Octavio. A questão nacional na América Latina. Estudos Avançados, v. 2, n. 1, p. 6-40, 1988.

JAGUARIBE, Helio. Dependencia y autonomía en América Latina. In: JAGUARIBE, Helio; FERRER, Aldo; WIONCZEK, Miguel; SANTOS, Theotonio dos. La dependencia político-económica de América Latina. Buenos Aires: Siglo Veintiuno, 1973, p. 1-85.

KAPLAN, Marcos. El Estado en el Desarrollo y la Integración de América Latina. Ensayos. Caracas: Monte Ávila Editores, 1969.

MEDEIROS, Marcelo de Almeida; BARNABÉ, Israel R.; ALBUQUERQUE, Rodrigo Barros; LIMA, Rafael. What does the field of international relations look like in South America. Revista Brasileira de Política Internacional, v. 59, n. 01, p. 1-31, 2016. 
Leonardo Granato

Ian Rebouças Batista
Cadernos Prolam/USP, v.16, n.31, p.5-29, jul./dez.2017

DOI: 10.11606/issn.1676-6288.prolam.2017.133966

MILIBAND, Ralph. O Estado na sociedade capitalista. Rio de Janeiro: Zahar, 1972.

MUHR, Thomas. Counter-hegemonic regionalism and higher education for all: Venezuela and the ALBA. Globalisation, Societies and Education, v. 8, n. 1, p. 39-57, 2010.

Venezuela and the ALBA: Counter-Hegemony, Geographies of Integration and Development and Higher Education for All. Saarbrücken: VDM, 2011.

O'DONNELL, Guillermo. Acerca del Estado, la democratización y algunos problemas conceptuales: Una perspectiva latinoamericana con referencias a países poscomunistas. Desarrollo Económico, v. 33, n. 130, p. 163-184, 1993.

Apuntes para una teoría del Estado. Revista Mexicana de Sociología, v. 40, n. 04, p. 1157-1199, oct./dic. 1978.

El Estado Burocrático Autoritario 1966-1973: Triunfos y derrotas. Buenos Aires: Editorial de Belgrano, 1982.

LINCK, Delfina. Dependencia y Autonomía. Formas de dependencia y estrategias de liberación. Buenos Aires: Amorrortu Editores, 1973.

ODDONE, Nahuel; GRANATO, Leonardo. La teoria dell'autonomia applicata ai nuovi processi di integrazione regionale latinoamericani. Il Politico: Rivista Italiana di Scienze Politique, n. 1, p. 183-200, jan./abr. 2009.

OLIVER-COSTILLA, Lucio Fernando. O Estado latino-americano perante a mundialização do capital. Revista de Ciências Sociais, v. 28, n. 1/2, p. 7-24, 1997.

OSZLAK, Oscar. Formación histórica del Estado en América Latina. Elementos teórico-metodológicos para su estudio. In: ACUÑA, Carlos H. (Comp.) Lecturas sobre el Estado y las políticas públicas. Retomando el debate de ayer para fortalecer el actual. Buenos Aires: Proyecto de Modernización del Estado: Jefatura de Gabinete de Ministros, [1978] 2007, p. 115-142.

PADULA, Raphael. A Geopolítica da Bacia do Pacífico e a integração regional na América do Sul. Revista do IMEA-UNILA, v. 01, n. 02, p. 30-47, 2013. 
PARADISO, José. Prólogo. In: CALDAS, Erick A. P.; GRANATO, Leonardo (Coords.). Integración Regional Sudamericana: Quo Vadis? Mossoró: Igramol, 2008, p. 10-13.

POULANTZAS, Nicos. Poder político y clases sociales en el Estado capitalista. México D. F.: Siglo Veintiuno, [1968] 2007.

PUIG, Juan Carlos. Doctrinas internacionales y autonomía latinoamericana. Caracas: Instituto de Altos Estudios de América Latina, Universidad Simón Bolívar, 1980.

Integración y autonomía de América Latina en las postrimerías del siglo XX. Integración Latinoamericana, n. 109, p. 40-62, ene./feb. 1986.

Introducción. In: PUIG, Juan Carlos (Comp.). América Latina: políticas exteriores comparadas. Buenos Aires: Grupo Editor Latinoamericano, 1984, pp. 24-90.

RAPOPORT, Mario. La globalización económica: ideologías, realidad, historia. Ciclos, n. 12, p. 3-42, 1997.

RIGGIROZZI, Pía; TUSSIE, Diana. The Rise of Post-Hegemonic Regionalism in Latin America. In: RIGGIROZZI, Pía; TUSSIE, Diana (Ed.). The Rise of Post-Hegemonic Regionalism. The case of Latin America. London: Springer, 2012, p. 1-16.

SARTI, Ingrid. Integração sul-americana, os desafios de um projeto estratégico. In: SARTI, Ingrid et al. (Orgs.). Os desafios da integração sul-americana: autonomia e desenvolvimento. Rio de Janeiro: Letra e Imagem, 2014, p. 7-12.

SCHMITTER, Philippe C. A experiência da integração europeia e seu potencial para a integração regional. Lua Nova, n. 80, p. 9-44, 2010.

SOARES DE LIMA, Maria Regina. Relações interamericanas: a nova agenda sulamericana e o Brasil. Lua Nova, n. 90, p. 167-201, 2013.

SÖDERBAUM, Fredrik. Rethinking Regionalism. London: Palgrave Macmillan, 2016. VEIGA, Pedro da Motta; RIOS, Sandra P. O regionalismo pós-liberal, na América do Sul: origens, iniciativas e dilemas. Santiago de Chile: CEPAL, 2007. 
WALLERSTEIN, Immanuel. The capitalist world-economy. Cambridge: Cambridge University Press, 1979.

WEYLAND, Kurt. Neoliberalism and Democracy in Latin America: A Mixed Record. Latin American Politics and Society, v. 46, n. 01, p. 135-157, 2004.

WEYLAND, Kurt; MADRID, Raúl L.; HUNTER, Wendy. The Policies and Performance of the Contestatory and Moderate Left. In: WEYLAND, Kurt; MADRID, Raúl L.; HUNTER, Wendy (Org.). Leftist Governments in Latin America: Successes and Shortcomings. Cambrigde: Cambridge University Press, 2010, p. 140-179.

ZAVALETA-MERCADO, René. El Estado en América Latina. Ensayos, n. 1, p. 59-78, 1984.

ZERMEÑO, Sergio. Las fracturas del Estado en América Latina. In: LECHNER, Norbert (Ed.). Estado y Política en América Latina. México D.F.: Siglo Veintiuno Editores, 1981, p. 60-86.

ZICCARDI, Natalia S. The Mexican Agenda in Latin America: The Pacific Alliance. Anuario de la Integración Regional de América Latina y el Gran Caribe, n. 10, p. 421436, 2014.

Recebido em 25/06/2017.

Aceito em 29/12/2017.

Publicado em 02/04/2018. 